\title{
Long-term effects (> 24 months) of multiple lifestyle intervention on major cardiovascular risk factors among high-risk subjects: a meta-analysis
}

\author{
Hilde Bergum ${ }^{1 *}$, Irene Sandven ${ }^{2}$ and Tor Ole Klemsdal ${ }^{3}$
}

\begin{abstract}
Background: The evidence of the long-term effects of multiple lifestyle intervention on cardiovascular risk is uncertain. We aimed to summarize the evidence from randomized clinical trials examining the efficacy of lifestyle intervention on major cardiovascular risk factors in subjects at high cardiovascular risk.

Methods: Eligible trials investigated the impact of lifestyle intervention versus usual care with minimum 24 months follow-up, reporting more than one major cardiovascular risk factor. A literature search updated April 15, 2020 identified 12 eligible studies. The results from individual trials were combined, using fixed and random effect models, using the standardized mean difference (SMD) to estimate effect sizes. Small-study effect was evaluated, and heterogeneity between studies examined, by subgroup and meta-regression analyses, considering patient- and study-level variables.

Results: Small-study effect was not identified. Lifestyle intervention reduced systolic blood pressure modestly with an estimated SMD of $-0.13,95 \%$ confidence interval $(\mathrm{Cl})$ : -0.21 to -0.04 , with moderate heterogeneity $\left(\mathrm{I}^{2}=59 \%\right)$, corresponding to a mean difference of approximately $2 \mathrm{mmHg}(\mathrm{MD}=-1.86,95 \% \mathrm{Cl}-3.14$ to $-0.57, p=0.0046)$. This effect disappeared in the subgroup of trials judged at low risk of bias $(S M D=0.02,95 \% \mathrm{Cl}-0.08$ to 0.11$)$. For the outcome total cholesterol SMD was $-0.06,95 \% \mathrm{Cl}-0.13$ to 0.00 , with no heterogeneity $\left(I^{2}=0 \%\right)$, indicating no effect of the intervention.

Conclusion: Lifestyle intervention resulted in only a modest effect on systolic blood pressure and no effect on total cholesterol after 24 months. Further lifestyle trials should consider the challenge of maintaining larger long-term benefits to ensure impact on cardiovascular outcomes.
\end{abstract}

Keywords: Lifestyle intervention, Primary prevention, Cardiovascular risk, Hypertension, Hypercholesterolemia

\section{Introduction}

Despite the decreases in cardiovascular mortality in recent decades, cardiovascular diseases (CVD) are still a leading cause of premature mortality $[1,2]$. The risk of

\footnotetext{
${ }^{*}$ Correspondence: hilde.bergum@|hl.no

${ }^{1}$ Department of Rehabilitation and Lifestyle Medicine, LHL-Hospital Gardermoen, Postboks 103 Jessheimbyen, 2051 Jessheim, Norway Full list of author information is available at the end of the article
}

CVD strongly relates to modifiable risk factors [3] and a dominant part (50-70\%) of the improvement in cardiovascular mortality can be ascribed to risk factor improvements in the population, while approximately $20-40 \%$ can be ascribed to better treatments $[4,5]$.

With convincing evidence relating risk factor levels to CVD morbidity and mortality, most current CVD prevention guidelines include lifestyle intervention as a key element [6-10]. Despite the broad recommendation of 
lifestyle advice, the long-term effects of multiple lifestyle intervention on cardiovascular risk factors appear sparsely documented.

Systematic reviews and meta-analyses show that lifestyle intervention does result in small reductions in risk factors including blood pressure, cholesterol and smoking when evaluated typically after 3-12 months [11-13]. Nevertheless, studies on lifestyle intervention have not been able to demonstrate a clear impact on coronary heart disease mortality or morbidity [11, 12]. This could be because the risk factor changes observed in studies of short duration are not maintained in the long term [11].

Most lifestyle studies report the effects of lifestyle intervention after 3-18 months, but few studies evaluate the effects beyond this time range. Since improvements in risk factor levels must be maintained over time, i.e. several years, to have an impact on cardiovascular events, it is of interest to elucidate the long-term effects of lifestyle intervention. The aim of this meta-analysis was to assess the long-term effects (i.e. after 24 months) of multiple lifestyle intervention on major cardiovascular risk factors i.e. total cholesterol (TC), systolic blood pressure (SBP) and smoking habits, in subjects with elevated cardiovascular risk from various causes.

\section{Methods}

The study was conducted and reported according to the PRISMA guidelines for meta-analyses and systematic reviews [14]. The protocol was published in the PROSPERO register (https://www.crd.york.ac.uk/prospero/), registration number CRD42018088783.

\section{Eligibility criteria}

We included randomized controlled clinical trials (RCTs) of cardiovascular primary prevention with a follow-up period of at least 24 months. To ensure that the findings would be relevant for the present situation, only studies published after 1990 were considered. Participants included had to be individually randomized.

\section{Patients}

Eligible studies included patients $\geq 40$ years without known CVD, but with at least one criteria of cardiovascular risk: hyperlipidemia, hypertension, cigarette smoking, obesity, inactivity, impaired glucose tolerance, the metabolic syndrome, or diabetes mellitus. Studies which included participants with diabetes mellitus were only included if only a minority $(<50 \%)$ of the participants had diabetes and if interventions were directed to reduce cardiovascular risk and not primarily blood glucose levels. Studies were excluded if the inclusion required presence of a specific medical condition.

\section{Intervention}

The intervention should be a health promotion activity that aimed to reduce total cardiovascular risk; i.e. to reduce more than one cardiovascular risk factor, through behavioral change, primarily related to diet and/or exercise; counseling or educational interventions, and with, or without, stable background pharmacological treatments.

\section{Comparison}

The studies should have a control group receiving usual care.

\section{Outcome variables}

Studies had to report the most important cardiovascular risk factors included in major algorithms for assessing total cardiovascular risk; i.e. SBP, TC and, if available, smoking habits.

\section{Search strategy}

A qualified medical librarian at the Medical Library, Oslo University Hospital, was consulted. RCTs published until April 15, 2020 were searched in PubMed, Embase and Cochrane Central Register of Controlled Trials. There were no language or date restrictions. Additional searches were also conducted in Cochrane Database of Systematic Reviews, UpToDate, NICE, and Prospero for ongoing systematic reviews.

In PubMed, Medical Subject Headings (MeSH Major Topic) and words in title were searched alone, or in combination, including lifestyle, primary prevention, combined modality therapy, risk reduction behavior, smoking cessation, diet, exercise, cardiovascular diseases, cardiovascular risk, hypertension, dyslipidemias and hypercholesterolemia. A more restrictive search strategy, including terms expressing lifestyle and cardiovascular risk, was then performed in Embase and Cochrane Central Register of Controlled Trials.

In addition, we manually screened reference lists of eligible papers and relevant systematic reviews.

\section{Study selection}

Two investigators ( $\mathrm{HB}, \mathrm{TOK})$ independently evaluated studies for possible inclusion. Non-relevant studies were excluded based on title and abstract. The remaining trials were evaluated in full text. Disagreements were resolved by discussion and subsequent consensus.

\section{Data abstraction}

Three reviewers (HB, TOK, IS) independently extracted information from each included trial using a pre-made data extraction form. Country of study origin, number 
of participants in the intervention and comparison groups, baseline frequency of males and current smokers, mean age of participants, body mass index (BMI), SBP, and TC was extracted.

\section{Endpoints variables}

Regarding the two main outcomes considered, change in SBP and total TC from baseline to follow-up, we extracted the mean difference and standard deviation of mean difference in the intervention and comparison group. As for change in smoking habits, we registered the number and frequency of smokers at baseline and follow up in each trial arm. Investigators were contacted for additional data when necessary.

A secondary outcome was change in estimated total cardiovascular risk from applied algorithms (i.e. Framingham, PROCAM). In interpreting the available data disagreements were resolved by discussion among the three reviewers (HMB, TOK, IS) and subsequent consensus.

\section{Risk of bias in individual studies}

Three reviewers (HMB, TOK, IS) independently assessed potential sources of bias specific to RCTs using the Cochrane Collaboration's tool [15]. Trials were classified as having an overall low risk of bias when the following core domains were judged at low risk of bias; concealment of randomization, blinding of outcome assessor, and intention-to-treat analyses.

\section{Quantitative data synthesis Statistical pooling}

In order to calculate an overall effect of intervention, the total standardized mean difference (SMD) with 95\% confidence interval (CI) was estimated (Cohen's method). If the value of zero is not included in the $95 \%$ $\mathrm{CI}$, then the SMD is statistically significant at the 5\% level $(p<0.05)$. Recommended interpretation is that a value of 0.2 indicates a small effect, 0.5 a medium effect, and of $\geq 0.8$ a large effect. Fixed and random effects model analyses were considered, and in presence of heterogeneity between trials we used the DerSimonian and Laird method [16].

\section{Sources of heterogeneity, evaluation and quantification}

Statistical heterogeneity among studies was assessed with Cochran's $Q$ test. The magnitude of heterogeneity was evaluated by the $\mathrm{I}^{2}$ statistics which describes the proportion of total variation due to heterogeneity rather than chance [17]. Potential sources of heterogeneity were investigated first by subgroup analyses. We stratified our data according to type of intervention (physical activity, diet, and both), and the following study characteristics: concealment of randomization, blinding of the endpoint assessors on allocated treatment and analysis according to intention-to-treat strategy. We extended the analyses by a random-effect meta-regression where the outcome variable was the observed SMD from every study, indicating treatment effect, and the different patient- and study-level characteristics (covariates). Source of heterogeneity was considered as important if the covariate decreased the between-study variance. The estimate of $\tau^{2}$, in the presence of a covariate in comparison to that when the covariate is omitted, allows the proportion of the heterogeneity variance explained by the covariate to be calculated [18].

A sensitivity analysis was undertaken to investigate the influence of each study by omitting each in turn from the meta-analysis, and assessing the degree to which the magnitude and significance of the intervention effect changed [19].

\section{Small-study effect}

Small-study effect was evaluated visually by the funnelplot and by Egger's test of asymmetry applied on the funnel-plot [20].

All statistical analyses were performed with STATA 15.0 [21] and R Package-meta [22].

\section{Results \\ Study selection}

After identifying 4315 references, 4283 were excluded due to irrelevant content and duplicate publication, leaving 32 potentially eligible studies that were examined more thoroughly. After evaluating the full texts of these 32 publications, twenty articles were excluded and twelve studies [23-34] were finally included in our meta-analysis (Fig. 1).

For six trials we obtained additional endpoint measures by communication with an author of these studies [23, $24,26,27,29,34]$. We estimated the standard deviation of mean difference from the reported standard error for two trials $[31,32]$ and from the $95 \%$ confidence interval for one trial [33]. For one trial we did not obtain a clarification from the authors whether the measure of variability presented was the standard deviation or the standard error [25]. We assumed it was the standard error since their measure was ten times lower than the standard deviation of the eleven other studies included in our meta-analysis.

\section{Study characteristics}

The 12 studies included 6350 patients from three geographical regions; North-America (6 trials), WesternEurope (5 trials) and Oceania (1 trial). Patient-related characteristics at baseline are shown in Table 1. The median age of the patients was 54 years (range 44-70), 

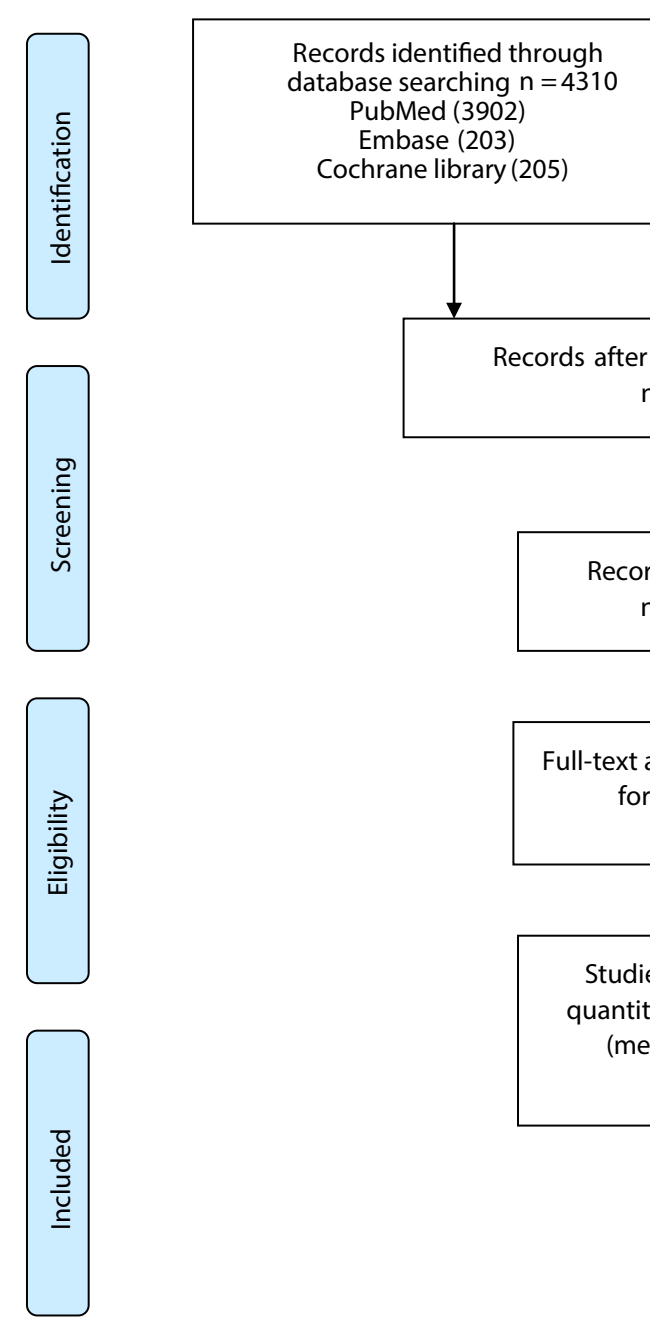

Records after duplicates removed $n=4000$

Additional records identified through other sources $\mathrm{n}=5$
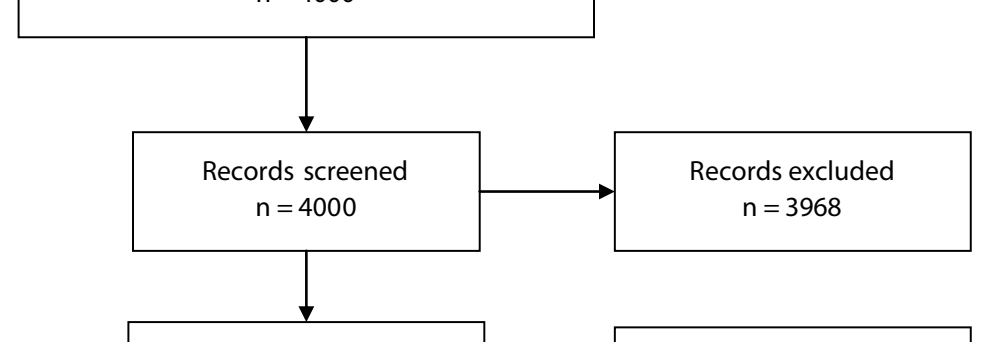

Full-text articles assessed for eligibility $\mathrm{n}=32$

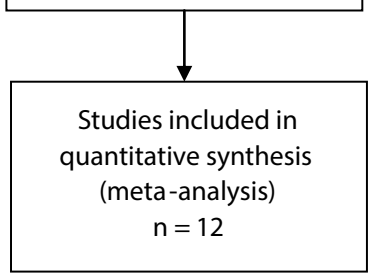

Full-text articles excluded, with reasons $\mathrm{n}=20$

Incomplete reporting of data (9) Study-population was not a high risk population (4)

Cholesterol not reported (2)

Intervention-group used more lipidlowering medication compared to usual care group (1)

Results not published (1)

The majority ( $>50 \%$ ) of the studypopulation had established cardiovascular disease (1)

Cluster-randomization (1)

Published before 1990 (1)

Fig. 1 PRISMA flow diagram of study selection from the literature searches for the systematic review of randomized clinical trials investigating the efficacy of long-term lifestyle intervention on major cardiovascular risk factors in adult high-risk subjects

$37.9 \%$ were males (range $0-100$ ) and $11.3 \%$ smokers (range 0-34). The median baseline value for SBP was $129.8 \mathrm{mmHg}$ (range 119.3-149), TC $5.5 \mathrm{mmol} / \mathrm{l}$ (range 4.4-6.3) and BMI $30.3 \mathrm{~kg} / \mathrm{m}^{2}$ (range 26.7-38.8). Median follow-up time was 24 months (range 24-36). Details concerning intervention components and study populations are given in Table 2.

\section{Risk of bias}

As shown in Table 3 randomization and adequate concealment were present in six trials [24-26, 28, 29, 34]. Blinding of participants and health professionals to intervention allocation throughout the twelve trials was impossible, due to the nature of the trials, and classified open labeled with potential risk of bias. Blinding of the endpoint assessor to treatment allocation was considered adequate in all trials for endpoint $\mathrm{TC}$, as laboratory staff presumably was unaware of subject group assignment. For endpoint SBP, blinding was reported in two trials $[29,34]$. Drop-out was present in eleven trials, ranging from 3 to $27 \%$ (median $11 \%$ ). Intention-to-treat strategy was reported in ten trials [23-25, 28-34]. A priori power estimation was presented in nine trials, but only one was adequate for the endpoints considered in our 
Table 1 Baseline characteristics of the 12 studies included in the meta-analysis

\begin{tabular}{|c|c|c|c|c|c|c|c|c|}
\hline First author (references) & $\begin{array}{l}\text { Intervention/ } \\
\text { comparison }(n / n)\end{array}$ & $\begin{array}{l}\text { Follow-up } \\
\text { (months) }\end{array}$ & $\begin{array}{l}\text { Age (years) } \\
\text { Mean }\end{array}$ & Males (\%) & $\begin{array}{l}\text { BMl } \\
\text { Mean }\end{array}$ & Smokers (\%) & $\begin{array}{l}\text { SBP } \\
\text { Mean }\end{array}$ & $\begin{array}{l}\text { TC } \\
\text { Mean }\end{array}$ \\
\hline Simons-Morton [34] & 289/292 & 24 & 51.3 & 54.7 & 29.8 & 8.4 & 119.3 & - \\
\hline Lindström [30] & $265 / 257$ & 24 & 55.0 & 33.0 & 31.2 & - & 138.0 & 5.60 \\
\hline Esposito [25] & $90 / 90$ & 24 & 43.9 & 55.0 & 28.0 & 0 & 135.0 & 5.08 \\
\hline Hjerkinn [27] & $139 / 142$ & 36 & 70.0 & 100 & 26.7 & 34.0 & 149.0 & 6.30 \\
\hline Ratner [31] & 1079/1082 & 24 & 50.4 & 31.5 & 34.1 & 6.7 & 123.5 & 5.3 \\
\hline Anderssen [23] & $142 / 143$ & 24 & 57.0 & 100 & 29.2 & 15.8 & 140.3 & 5.97 \\
\hline Lawton [29] & $544 / 545$ & 24 & 58.9 & 0 & 29.2 & 12.6 & 123.1 & 6.07 \\
\hline Eriksson [24] & $71 / 74$ & 24 & 54.4 & 42.8 & 29.8 & 20.7 & 145.5 & 5.46 \\
\hline Kuller [28] & $253 / 255$ & 30 & 57.0 & 0 & 30.8 & 6.0 & 124.1 & 5.51 \\
\hline Vetter [32] & $131 / 130$ & 24 & 51.9 & 20.3 & 38.8 & 10.0 & 121.9 & 4.85 \\
\hline Goyer [26] & $62 / 62$ & 24 & 54.4 & 67.8 & 31.9 & 21.8 & 137.5 & 5.45 \\
\hline Lee [33] & $103 / 104$ & 24 & 51.7 & 20.3 & 36.6 & - & 124.5 & 4.4 \\
\hline
\end{tabular}

BMI, body mass index $\left(\mathrm{kg} / \mathrm{m}^{2}\right)$; SBP, systolic blood pressure $(\mathrm{mmHg}) ; \mathrm{TC}$, total cholesterol $(\mathrm{mmol} / \mathrm{l})$

Table 2 Study characteristics

\begin{tabular}{|c|c|c|c|c|c|}
\hline Study & Year & Country & Population & Intervention & Comparison \\
\hline Simons-Morton [34] & 2001 & USA & Inactive adults & $\begin{array}{l}\text { Physical activity } \\
\text { Advice/counseling, telephone } \\
\text { contacts, interactive mail-con- } \\
\text { tacts, self-monitoring devices }\end{array}$ & Physician advice \\
\hline Lindström (30) & 2003 & Finland & $\begin{array}{l}\text { Overweight/obese adults with } \\
\text { IGT }\end{array}$ & $\begin{array}{l}\text { Physical activity and diet. Advice/ } \\
\text { counseling, exercise sessions }\end{array}$ & General information \\
\hline Esposito [25] & 2004 & Italy & $\begin{array}{l}\text { Sedentary adults with metabolic } \\
\text { syndrome }\end{array}$ & $\begin{array}{l}\text { Diet } \\
\text { Advice/counseling }\end{array}$ & $\begin{array}{l}\text { General information + bi-monthly } \\
\text { sessions }\end{array}$ \\
\hline Hjerkinn [27] & 2005 & Norway & $\begin{array}{l}\text { Elderly men with long standing } \\
\text { hyperlipidemia }\end{array}$ & $\begin{array}{l}\text { Diet } \\
\text { Advice/counseling, placebo } \\
\text { capsules (omgega-3) }\end{array}$ & Placebo-capsules (omega-3) \\
\hline Ratner [31] & 2005 & USA & Overweight adults with IGT & $\begin{array}{l}\text { Physical activity and diet } \\
\text { Advice/counseling, exercise } \\
\text { sessions }\end{array}$ & $\begin{array}{l}\text { General information + annual } \\
\text { individual sessions + placebo } \\
\text { (Metformin) }\end{array}$ \\
\hline Anderssen [23] & 2005 & Norway & $\begin{array}{l}\text { Sedentary, overweight/obese } \\
\text { men on antihypertensive drug } \\
\text { treatment, elevated TC }\end{array}$ & $\begin{array}{l}\text { Physical activity and diet } \\
\text { Advice/counseling, exercise ses- } \\
\text { sions, placebo (Fluvastatin) }\end{array}$ & $\begin{array}{l}\text { Usual care by own general practi- } \\
\text { tioner + placebo (Fluvastatin) }\end{array}$ \\
\hline Lawton [29] & 2008 & New Zealand & Inactive women & $\begin{array}{l}\text { Physical activity } \\
\text { Advice/counseling, telephone } \\
\text { contacts }\end{array}$ & $\begin{array}{l}\text { Usual care from primary care } \\
\text { practice }\end{array}$ \\
\hline Eriksson [24] & 2009 & Sweden & $\begin{array}{l}\text { Adults with hypertension, dys- } \\
\text { lipidemia, T2DM, obesity or any } \\
\text { combination thereof }\end{array}$ & $\begin{array}{l}\text { Physical activity and diet } \\
\text { Advice/counseling, exercise } \\
\text { sessions }\end{array}$ & $\begin{array}{l}\text { General information + examination } \\
\text { at 3,12, } 24 \text { and } 36 \text { months }\end{array}$ \\
\hline Kuller [28] & 2012 & USA & Overweight/obese women & $\begin{array}{l}\text { Physical activity and diet } \\
\text { Advice/counseling }\end{array}$ & $\begin{array}{l}6 \text { Seminars first year with focus on } \\
\text { women`s health, several times } \\
\text { per year thereafter }\end{array}$ \\
\hline Vetter [32] & 2013 & USA & $\begin{array}{l}\text { Obese adults with at least one } \\
\text { other criterion for metabolic } \\
\text { syndrome }\end{array}$ & $\begin{array}{l}\text { Physical activity and diet } \\
\text { Advice/counseling }\end{array}$ & $\begin{array}{l}\text { Quarterly primary care provider } \\
\text { visits }\end{array}$ \\
\hline Goyer [26] & 2013 & Canada & $\begin{array}{l}\text { Adults with } \mathrm{BMI} \geq 30 \mathrm{~kg} / \mathrm{m}^{2} \text { and } \\
\text { at least } 2 \text { cardio-vascular risk } \\
\text { factors: elevated SBP or DBP, } \\
\text { elevated } \mathrm{LDL} \text {, elevated TC/HDL, } \\
\text { uncontrolled T2DM, smoking }\end{array}$ & $\begin{array}{l}\text { Physical activity, diet and stress } \\
\text { management } \\
\text { Advice/counseling, exercise } \\
\text { sessions }\end{array}$ & $\begin{array}{l}\text { Usual care (family physician). } \\
\text { At } 1 \text { year contact for address } \\
\text { verification + reminder of } 2 \text { year } \\
\text { follow-up }\end{array}$ \\
\hline Lee (33) & 2015 & USA & $\begin{array}{l}\text { American Indians with } \mathrm{BMI} \geq 25 \\
\text { and metabolic syndrome }\end{array}$ & $\begin{array}{l}\text { Physical activity and diet } \\
\text { Advice/counseling, exercise } \\
\text { sessions }\end{array}$ & $\begin{array}{l}\text { Information by mail. Follow-up } \\
\text { assessments every } 6 \text { months }\end{array}$ \\
\hline
\end{tabular}


Table 3 Authors' risk of bias assessment for the 12 studies included in the meta-analysis

\begin{tabular}{|c|c|c|c|c|c|c|c|}
\hline \multirow[t]{3}{*}{ First author (references) } & \multicolumn{2}{|c|}{ Selection bias } & \multirow{3}{*}{$\begin{array}{l}\text { Performance bias } \\
\text { Blinding of } \\
\text { participants and } \\
\text { personnel }^{\mathrm{a}}\end{array}$} & \multirow{2}{*}{\multicolumn{2}{|c|}{$\begin{array}{l}\text { Detection bias } \\
\text { Blinding of } \\
\text { outcome } \\
\text { assessment }\end{array}$}} & \multirow{3}{*}{$\begin{array}{l}\text { Attrition bias } \\
\text { Incomplete } \\
\text { outcome data }\end{array}$} & \multirow{3}{*}{$\begin{array}{l}\text { Other sources of bias } \\
\text { Intention to treat analysis }\end{array}$} \\
\hline & \multirow[t]{2}{*}{$\begin{array}{l}\text { Random } \\
\text { sequence } \\
\text { generation }\end{array}$} & \multirow[t]{2}{*}{$\begin{array}{l}\text { Allocation } \\
\text { concealment }\end{array}$} & & & & & \\
\hline & & & & SBP & TC & & \\
\hline Simons-Morton [34] & Low & Low & High & Low & Low & Unclear & Low \\
\hline Lindström [30] & Low & Unclear & High & Unclear & Low & Unclear & Low \\
\hline Esposito [25] & Low & Low & High & Unclear & Low & Unclear & Low \\
\hline Hjerkinn [27] & Unclear & Unclear & High & Unclear & Low & Unclear & Unclear \\
\hline Ratner [31] & Unclear & Unclear & High & Unclear & Low & Unclear & Low \\
\hline Anderssen [23] & Unclear & Unclear & High & Unclear & Low & Unclear & Low \\
\hline Lawton [29] & Low & Low & High & Low & Low & Unclear & Low \\
\hline Eriksson [24] & Low & Low & High & Unclear & Low & Unclear & Low \\
\hline Kuller [28] & Low & Low & High & Unclear & Low & Unclear & Low \\
\hline Vetter [32] & Low & Unclear & High & Unclear & Low & Unclear & Low \\
\hline Goyer [26] & Low & Low & High & Unclear & Low & Unclear & Unclear \\
\hline Lee [33] & Unclear & Unclear & High & Unclear & Low & Unclear & Low \\
\hline
\end{tabular}

Risk of bias graded as low, high, unclear

SBP, systolic blood pressure; TC, total cholesterol

a All trials were judged open labeled

meta-analysis [29]. In summary, two of the included trials represented high-quality according to concealment of randomization, blinding of outcome assessor and intention-to-treat analyses $[29,34]$.

\section{Synthesis of results}

\section{Endpoint SBP}

The pooled estimate from 12 studies indicated a small effect of lifestyle intervention on SBP (SMD $=-0.13,95 \%$ $\mathrm{CI}-0.21$ to $-0.04, p=0.0048)$, with moderate heterogeneity $\left(\mathrm{I}^{2}=59 \%\right)$ (Fig. $\left.2 \mathrm{a}\right)$. The absolute difference between the mean value in intervention versus comparison group was approximately $2 \mathrm{mmHg}(\mathrm{MD}=-1.86,95 \% \mathrm{CI}-3.14$ to $-0.57, p=0.0046$ ).

When stratifying on type of intervention, difference in the pooled estimates was mostly observed between the two groups consisting of physical activity only (SMD $=0.02,95 \% \mathrm{CI}-0.08$ to 0.11 ) or diet only (SMD $=-0.12,95 \% \mathrm{CI}-0.31$ to 0.06 ), and the group with a combination of physical activity and diet $(\mathrm{SMD}=-0.18,95 \% \mathrm{CI}-0.28$ to -0.08$)$. Considering the trials satisfying three major parameters of internal validity, no effect of lifestyle intervention was demonstrated (SMD $=0.02,95 \% \mathrm{CI}-0.08$ to 0.11 ), while for the trials with non-presence of all three conditions a small effect was found (SMD $=-0.17,95 \% \mathrm{CI}$ -0.25 to -0.09$)$. Extending the analysis with metaregression, the study quality was associated with the effect of lifestyle intervention ( $p=0.0136)$, accounting for $68 \%$ of the observed heterogeneity. None of the patient-related variables considered (mean age, mean BMI, frequency of male sex and frequency of smokers) were significantly associated with intervention effect. There was no indication of small-study effect as the funnel plot visually appeared symmetrical (Fig. 3a), supported by Egger's test $(p=0.921)$. The robustness of the pooled effect was demonstrated by influential analysis. Whatever study we omitted, the pooled estimate did not change in magnitude, direction or statistical significance.

\section{Endpoint TC}

The pooled estimate from ten studies (Fig. 2b) indicated no significant effect of lifestyle intervention on total cholesterol $(\mathrm{SMD}=-0.06(95 \% \mathrm{CI}-0.13$ to $0.00, p=0.0634)$, with no heterogeneity $\left(\mathrm{I}^{2}=0 \%\right)$. The absolute difference between the mean value in intervention versus comparison group was $0.05 \mathrm{mmol} / \mathrm{l}$ $(\mathrm{MD}=-0.05,95 \% \mathrm{CI}-0.11$ to $0.00, p=0.0495)$. Subgroup analysis and meta-regression were not indicated since there was no observed heterogeneity between the trials. No indication of small-study effect was found as the funnel-plot visually appeared symmetrical (Fig. 3b), confirmed by Egger's test $(p=0.893)$. A stable pooled estimate was demonstrated by influential analysis, omitting one study at a time from the meta-analysis. 


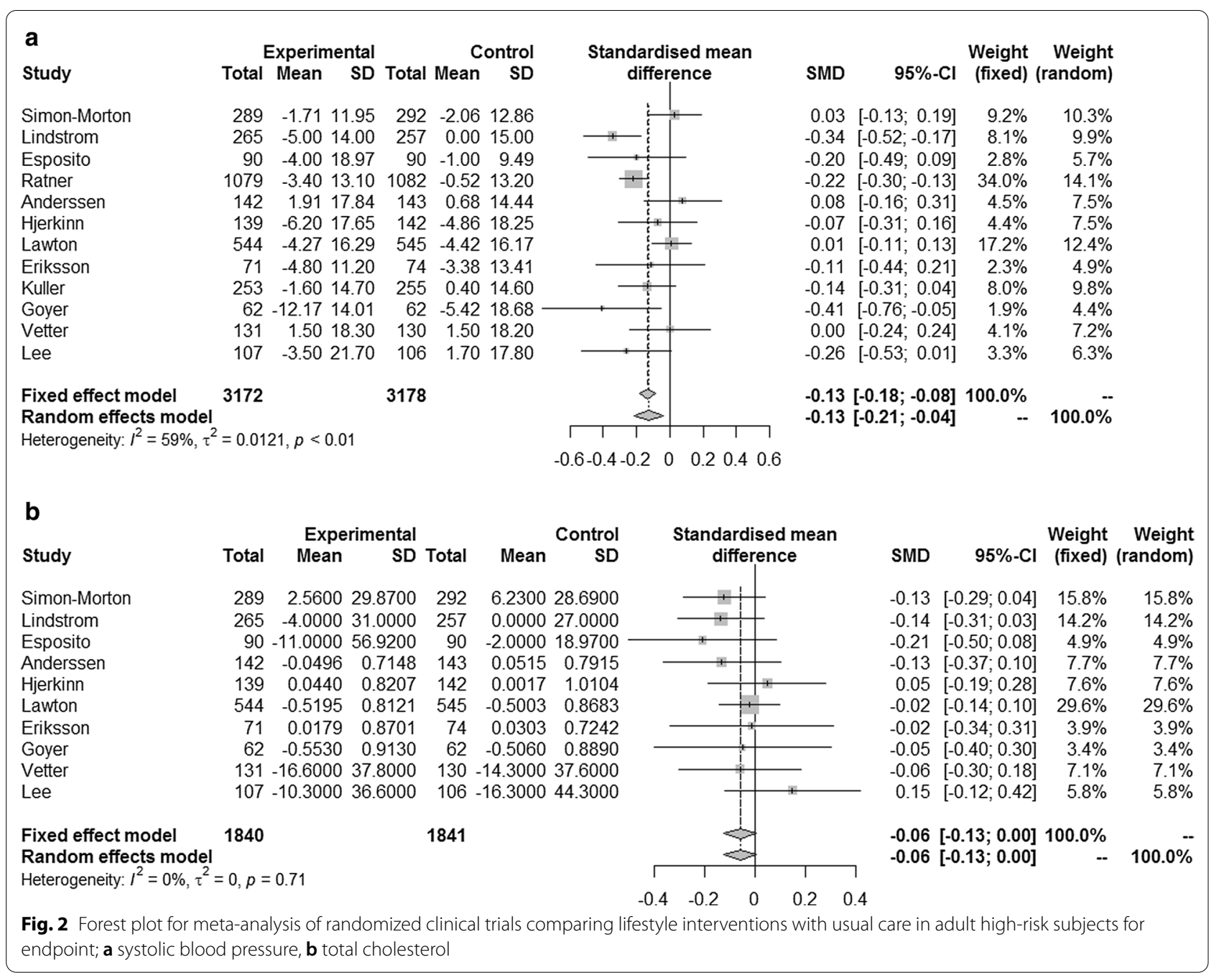

\section{Smoking habits}

After receiving follow-up information, four studies reported on change in smoking habits [24, 26, 31, 34]. Two of these studies $[24,26]$ demonstrated that the proportion of current smokers at follow-up were lower than at baseline in the intervention groups, while no change in the control groups.

\section{Total cardiovascular risk}

Only one study [26] reported on change in total cardiovascular risk applied from algorithms (Framingham, PROCAM). This trial showed that the 10-year Framingham cardiovascular risk declined from 16 to $14.6 \%$ in the intervention group compared to an increase from 14.3 to $19.1 \%$ in the control group, bearing in mind that the changes in both groups also were affected by the fact that the participants gained 2 years of age during the study. The PROCAM cardiovascular risk calculations declined in both groups.

\section{Discussion}

The main result of this meta-analysis of RCTs examining long-term effects of lifestyle intervention indicates a limited effect on major cardiovascular risk factors SBP and TC. Regarding smoking cessation there was numerically greater reduction in smoking rates in the intervention groups compared to the comparison groups.

The limited long-term effect of lifestyle intervention may seem in contrast to the great importance lifestyle intervention has been given in guidelines on cardiovascular prevention [6-10]. As an example, the 2019 ACC/ AHA Guideline reports that lifestyle intervention with 6 different elements including diet and exercise may each reduce SBP by at least $4 \mathrm{mmHg}$ in hypertensive subjects and $2 \mathrm{mmHg}$ in normotensives, suggesting larger effects of combined measures [9]. However, the guideline does not specify the duration of the expected effects. From the Look Ahead study [35], the challenge of maintaining the benefits of lifestyle intervention on blood pressure (and 

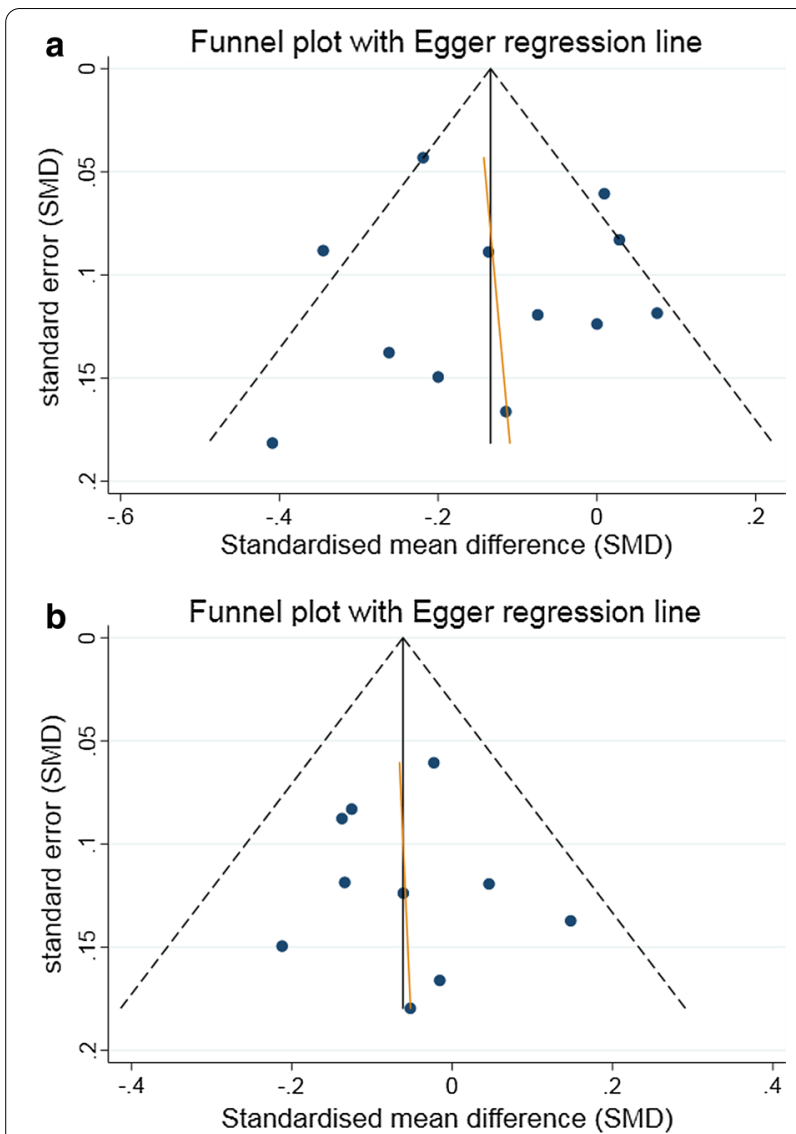

Fig. 3 Funnel plot of the effect of lifestyle interventions for endpoint a systolic blood pressure, $\mathbf{b}$ total cholesterol

other parameters) is evident: At 12 months, SBP was reduced by $6,8 \mathrm{mmHg}$ in the intensive lifestyle group compared to $2,8 \mathrm{mmHg}$ in the standard care group. However, averaged across the first 4 years, the difference in SBP was reduced by 5.33 versus $2.97 \mathrm{~mm} \mathrm{Hg}$; i.e. a difference of $2.36 \mathrm{mmHg}$, very similar to the results in our meta-analysis.

A small effect on SBP, but no effect on TC, was similarly reported in the Finnish Diabetes Prevention Study [30], where SBP were lowered by $5 \mathrm{mmHg}$ after 2 years while TC remained unchanged. Also the American Diabetes Prevention Program demonstrated significantly greater decrease in SBP in the lifestyle group $(-3.4 \mathrm{mmHg} \pm 0.4)$ compared to control group $(-0.52 \mathrm{mmHg} \pm 0.4)$, but no changes in the TC levels [31].

In the meta-analysis from 2018 by Sisti et al. [13], both SBP and TC were significantly lowered after 6 months. The decrease in SBP was $-5.20 \mathrm{mmHg}(95 \%$ $\mathrm{CI}-9.4,-1.07)$ after 6 months and $-3.20 \mathrm{mmHg}(95 \%$ CI -4.56 to 1.84 ) after 12 months. TC was lowered by $-0.36 \mathrm{mmol} / \mathrm{l}(95 \% \mathrm{CI}-0.63$ to 0.10$)$ after 6 months and $-0.23 \mathrm{mmol} / \mathrm{l}(95 \% \mathrm{CI}-0.39$ to 0.08$)$ after 12 months.
Almost identical findings were reported from Ebrahim's Cochrane review [11] where the reduction of SBP was $-2.71 \mathrm{mmHg}(95 \% \mathrm{CI}-3.49$ to 1.93$)$ while TC levels dropped by $-0.07 \mathrm{mmol} / \mathrm{L}$ ( $95 \% \mathrm{CI}-0.08$ to 0.06 ) after 12 months.

In summary, major lifestyle studies and meta-analyses show that lifestyle intervention result in small, but significant changes in SBP and TC after 6-12 months. However, the benefits gradually attenuate over time, especially regarding TC. Our study confirms this attenuation of benefits and demonstrates further reductions in the period from 12 to 24 months.

Trials examining lifestyle intervention should ideally have clinical endpoints, as the ultimate goal is reducing cardiovascular events. Trials with clinical outcomes are large and costly, however, which explains why most lifestyle intervention trials instead focus on improvements in established cardiovascular risk factors. Reviews so far have reported effects after 3-12 months, and occasionally up to 18 months, motivating our attention to study the effects after longer follow-up. Ideally, however, even longer follow-up, i.e. 5-10 years, would be optimal to substantiate the clinical value of the interventions. From our literature search, such data appear very limited.

The present study demonstrates that a small reduction in SBP of approximately $2 \mathrm{mmHg}$ may be maintained over time with lifestyle intervention. This was observed in a population with mean baseline SBP of $129 \mathrm{mmHg}$ and many studies report that greater reductions may be achieved when the baseline blood pressure is higher [9, 36]. Although the effect of lifestyle intervention appears small, a reduction of this size may result in a valuable reduce in the risk of future CVD, according to epidemiological evidence and studies evaluating benefits of sodium reduction in the population [36], that suggested that a reduction of $3.8 \mathrm{mmHg}$ could prevent 1,6 million annual CVD deaths globally.

While a limited effect on SBP was observed, we found no effect on cholesterol levels. The reasons for the lack of efficacy are unclear, but may relate to the intensity of the intervention, the quality of the dietary and exercise advice and to difficulties in maintaining lifestyle changes over time. Since several studies of short duration, i.e. 3-6 months, have reported considerably larger effects on blood pressure [37], and to some extent on cholesterol $[38,39]$, the latter explanation may appear the most important.

Traditional lifestyle interventions have had cholesterol levels and smoking cessation as the main targets [40, 41]. However, both smoking rates and cholesterol levels have been significantly reduced in most western populations the last decades, the latter mainly due to general improvements in the population diet, for example with 
reductions in trans fat [42]. Accordingly, reduction in cholesterol levels through diet modifications may have become harder to achieve. Hence, the most feasible target for risk reduction through lifestyle interventions in non-smokers may now have become a reduction in SBP.

The results in our meta-analysis highlight the need to develop strategies that enable high-risk individuals to maintain the effects on risk factors beyond 3-6 months. At present, we do not know if the attenuation of the effects is entirely related to a reduced compliance/ patient fatigue regarding lifestyle habits, or if it may also represent some sort of physiological adaptation to the obtained lifestyle changes. A further possibility is that the advices used in the included studies are no longer optimal, and need to be revised according to the contemporary risk profile and lifestyle challenges in the population.

\section{Strengths and limitations}

This meta-analysis is, to the best of our knowledge, the first addressing the impact of multiple lifestyle intervention on cardiovascular risk factors in the long-term; i.e. after 24 months.

Our review was based on a comprehensive literature search, which reduces the possibility of missing relevant trials [43]. Trial selection was done by two authors, and data extraction by three authors, to minimize transcription errors. As recommended by the Cochrane Collaboration tools for assessing risk of bias in randomized trials [15], we did not use summary scores to identify quality of trials. The components used for quality assessment are validated and reported to be associated with bias [44]. The analysis applied the recommended principles for meta-analysis methodology regarding eligibility criteria for the individual trials, analysis methods to explore sources of heterogeneity between studies and evaluate small-study effect [45].

Small-study effect was unlikely to affect our results. A major limitation was the observed heterogeneity between trials. Our results concerning the efficacy of lifestyle intervention on SBP was altered when stratifying on the components of trial quality, and meta-regression demonstrated that trial quality was an important determinant of the intervention effect. The impact of study-level variables on meta-analysis results has been investigated, indicating true associations between heterogeneous treatment effects and the study-level variables [46]. On the other hand, the diversity could be related to differences in the patient population studied and differences in interventions. The population in the two trials classified as having an overall low risk of bias $[29,34]$ was normotensive, making it less likely to expect a significant SBP reduction. Moreover, the intervention in these two trials consisted of physical activity only, which quite likely may have reduced the impact of the intervention compared to trials also including dietary advice.

The review considered trials published after 1990 only. Of the 4315 records identified, only 12 trials could be included, illustrating the sparse number of RCTs with follow-up time as long as 24 months and sufficient data to be evaluated.

\section{Future directions}

A final answer on the efficacy of lifestyle interventions for reducing cardiovascular risk would require RCTs large enough to evaluate effects on clinical outcomes, but such trials would have to be very large and costly, as exemplified by the Look AHEAD study [35]. A more feasible approach could be the use of proper validated risk algorithms as primary outcomes, as these integrate the effects on multiple risk factors and allow valuable estimates of the intervention on total cardiovascular risk. Meanwhile, further trials should focus on the challenge of maintaining the benefits often reported in studies of 6-12 months duration. In this respect it is worth noting that the most feasible targets for risk reduction may now have become reduction in SBP and smoking cessation, as reductions in cholesterol levels through diet counseling seem hard to achieve.

\section{Conclusion}

In conclusion, our results suggest that the effects of lifestyle intervention on major cardiovascular risk factors after 24 months of follow-up are limited, but a modest effect on SBP may be of clinical relevance. Our observations demonstrate the challenge of maintaining benefits during longer follow-up, and suggest a need to develop new strategies to promote durable changes in cardiovascular risk.

\begin{abstract}
Abbreviations
CVD: Cardiovascular disease; TC: Total cholesterol; SBP: Systolic blood pressure; RCT: Randomized controlled clinical trial; BMI: Body mass index; SMD: Standardized mean difference; IGT: Impaired glucose tolerance; T2DM: Type 2 diabetes mellitus; DBP: Diastolic blood pressure.
\end{abstract}

\section{Supplementary Information}

The online version contains supplementary material available at https://doi. org/10.1186/s12872-021-01989-5.

Additional file 1. Title page, not relevant as supporting document as its content is covered in the title-page in the publication.

Additional file 2. Datafile on endpoint SBP.

Additional file 3. Datafile on endpoint SBP.

Additional file 4. Datafile on endpoint Tchol. 


\section{Additional file 5. Datafile on endpoint Tchol.}

\section{Acknowledgements}

The authors would like to thank Marie Susanna Isachsen, medical librarian at the Medical Library, Oslo University Hospital, for her assistance with the literature search.

\section{Authors' contributions}

All review authors contributed to conception and design, acquisition of data, analysis and interpretation of data, drafting and revising the article critically for important intellectual content, gave final approval of the version to be published, and agree to be accountable for all aspects of the work. All authors read and approved the final manuscript.

\section{Funding}

First-author's salary is partly funded in a grant from the Norwegian health department.

\section{Availability of data and materials}

All data generated and analysed during this study are included in this article and its supplementary information files.

\section{Declarations}

Ethics approval and consent to participate

Not applicable.

\section{Consent for publication}

Not applicable.

\section{Competing interests}

The authors declare that they have no competing interests.

\section{Author details}

${ }^{1}$ Department of Rehabilitation and Lifestyle Medicine, LHL-Hospital Gardermoen, Postboks 103 Jessheimbyen, 2051 Jessheim, Norway. ${ }^{2}$ Oslo Centre for Biostatistics and Epidemiology (OCBE), Oslo University Hospital, Oslo, Norway. ${ }^{3}$ Department of Preventive Cardiology, Oslo University Hospital, Oslo, Norway.

Received: 20 October 2020 Accepted: 5 April 2021

Published online: 15 April 2021

\section{References}

1. Townsend N, Wilson L, Bhatnagar P, et al. Cardiovascular disease in Europe: epidemiological update 2016. Eur Heart J. 2016;37(42):3232-45.

2. Benjamin EJ, Virani SS, Callaway CW, et al. Heart disease and stroke statistics-2018 update: a report from the American Heart Association. Circulation. 2018;137(12):e67-492.

3. Yusuf S, Hawken S, Ounpuu S, et al. Effect of potentially modifiable risk factors associated with myocardial infarction in 52 countries (the INTERHEART study): case-control study. Lancet. 2004;364(9438):937-52.

4. Mannsverk J, Wilsgaard T, Mathiesen EB, et al. Trends in modifiable risk factors are associated with declining incidence of hospitalized and nonhospitalized acute coronary heart disease in a population. Circulation. 2016;133(1):74-81.

5. Mensah GA, Wei GS, Sorlie PD, et al. Decline in cardiovascular mortality: possible causes and implications. Circ Res. 2017;120(2):366-80.

6. Piepoli MF, Hoes AW, Agewall S, et al. 2016 European Guidelines on cardiovascular disease prevention in clinical practice: The Sixth Joint Task Force of the European Society of Cardiology and Other Societies on Cardiovascular Disease Prevention in Clinical Practice (constituted by representatives of 10 societies and by invited experts) developed with the special contribution of the European Association for Cardiovascular Prevention \& Rehabilitation (EACPR). Eur Heart J. 2016;37(29):2315-81.
7. Joint British Societies' consensus recommendations for the prevention of cardiovascular disease (JBS3). Heart. 2014;100(Suppl) 2:ii1-67.

8. National Clinical Guideline C. National Institute for Health and Clinical Excellence: Guidance. Lipid Modification: Cardiovascular Risk Assessment and the Modification of Blood Lipids for the Primary and Secondary Prevention of Cardiovascular Disease. London: National Institute for Health and Care Excellence (UK) Copyright (c) National Clinical Guideline Centre, 2014.

9. Arnett DK, Blumenthal RS, Albert MA, et al. 2019 ACC/AHA guideline on the primary prevention of cardiovascular disease: executive summary: a report of the American College of Cardiology/American Heart Association Task Force on Clinical Practice Guidelines. Circulation. 2019;140(11):e563-95.

10. Grundy SM, Stone NJ, Bailey AL, et al. 2018 AHA/ACC/AACVPR/AAPA/ ABC/ACPM/ADA/AGS/APhA/ASPC/NLA/PCNA guideline on the management of blood cholesterol a report of the American College of Cardiology/American Heart Association Task Force on Clinical Practice Guidelines. J Am Coll Cardiol. 2019;73(24):e285-350.

11. Ebrahim S, Taylor F, Ward K, et al. Multiple risk factor interventions for primary prevention of coronary heart disease. Cochrane Database Syst Rev. 2011;1:Cd001561.

12. Patnode CD, Evans CV, Senger CA, et al. Behavioral counseling to promote a healthful diet and physical activity for cardiovascular disease prevention in adults without known cardiovascular disease risk factors: updated evidence report and systematic review for the US preventive services task force. JAMA. 2017;318(2):175-93.

13. Sisti LG, Dajko M, Campanella P, et al. The effect of multifactorial lifestyle interventions on cardiovascular risk factors: a systematic review and meta-analysis of trials conducted in the general population and high risk groups. Prev Med. 2018;109:82-97.

14. Liberati A, Altman DG, Tetzlaff J, et al. The PRISMA statement for reporting systematic reviews and meta-analyses of studies that evaluate healthcare interventions: explanation and elaboration. BMJ. 2009;339:b2700-b.

15. Higgins JP, Altman DG, Gotzsche PC, et al. The Cochrane Collaboration's tool for assessing risk of bias in randomised trials. BMJ. 2011:343:d5928.

16. DerSimonian R, Laird N. Meta-analysis in clinical trials revisited. Contemp Clin Trials. 2015;45(Pt A):139-45.

17. Higgins JPT, Thompson SG, Deeks JJ, et al. Measuring inconsistency in meta-analyses. BMJ (Clin Res ed). 2003;327(7414):557-60

18. Thompson SG, Higgins JP. How should meta-regression analyses be undertaken and interpreted? Stat Med. 2002;21(11):1559-73.

19. Viechtbauer W, Cheung MW. Outlier and influence diagnostics for metaanalysis. Res Synth Methods. 2010;1(2):112-25.

20. Egger M, Davey Smith G, Schneider M, et al. Bias in meta-analysis detected by a simple, graphical test. BMJ. 1997;315(7109):629-34

21. StatCorp LLC. College Station TX, USA. http://www.stata.com. Accessed 01 Oct 2020

22. Schwarzer G. Meta: an R package for meta-analysis. 2007;7:40-5.

23. Anderssen SA, Hjelstuen AK, Hjermann I, et al. Fluvastatin and lifestyle modification for reduction of carotid intima-media thickness and left ventricular mass progression in drug-treated hypertensives. Atherosclerosis. 2005;178(2):387-97.

24. Eriksson MK, Franks PW, Eliasson M. A 3-year randomized trial of lifestyle intervention for cardiovascular risk reduction in the primary care setting: the Swedish Bjorknas study. PLoS ONE. 2009:4(4):e5195.

25. Esposito K, Marfella R, Ciotola M, et al. Effect of a mediterranean-style diet on endothelial dysfunction and markers of vascular inflammation in the metabolic syndrome: a randomized trial. JAMA. 2004;292(12):1440-6.

26. Goyer L, Dufour R, Janelle C, et al. Randomized controlled trial on the long-term efficacy of a multifaceted, interdisciplinary lifestyle intervention in reducing cardiovascular risk and improving lifestyle in patients at risk of cardiovascular disease. J Behav Med. 2013;36(2):212-24.

27. Hjerkinn EM, Seljeflot I, Ellingsen I, et al. Influence of long-term intervention with dietary counseling, long-chain n-3 fatty acid supplements, or both on circulating markers of endothelial activation in men with longstanding hyperlipidemia. Am J Clin Nutr. 2005:81(3):583-9.

28. Kuller LH, Pettee Gabriel KK, Kinzel LS, et al. The women on the move through activity and nutrition (WOMAN) study: final 48-month results. Obesity (Silver Spring, Md). 2012;20(3):636-43. 
29. Lawton BA, Rose SB, Elley CR, et al. Exercise on prescription for women aged 40-74 recruited through primary care: two year randomised controlled trial. BMJ. 2008;337:a2509.

30. Lindstrom J, Eriksson JG, Valle TT, et al. Prevention of diabetes mellitus in subjects with impaired glucose tolerance in the Finnish Diabetes Prevention Study: results from a randomized clinical trial. J Am Soc Nephrol. 2003:14(7 Suppl 2):S108-13.

31. Ratner R, Goldberg R, Haffner S, et al. Impact of intensive lifestyle and metformin therapy on cardiovascular disease risk factors in the diabetes prevention program. Diabetes Care. 2005;28(4):888-94.

32. Vetter ML, Wadden TA, Chittams J, et al. Effect of lifestyle intervention on cardiometabolic risk factors: results of the POWER-UP trial. Int J Obes (Lond). 2013;37(Suppl 1):S19-24.

33. Lee E. Results and lessons learned from a cardiovascular risk reduction program for American Indians-The Balance Study. International Journal of Health and Nutrition. 2015.

34. Simons-Morton, et al. Effects of physical activity counseling in primary care: the Activity Counseling Trial: a randomized controlled trial. JAMA. 2001;286(6):677-87.

35. Wing RR. Long-term effects of a lifestyle intervention on weight and cardiovascular risk factors in individuals with type 2 diabetes mellitus: four-year results of the Look AHEAD trial. Arch Intern Med. 2010;170(17):1566-75

36. Mozaffarian D, Fahimi S, Singh GM, et al. Global sodium consumption and death from cardiovascular causes. N Engl J Med. 2014;371(7):624-34.

37. Sacks FM, Svetkey LP, Vollmer WM, et al. Effects on blood pressure of reduced dietary sodium and the dietary approaches to stop hypertension (DASH) diet: DASH-sodium collaborative research group. N Engl J Med. 2001;344(1):3-10

38. Welty FK, Stuart E, O'Meara M, et al. Effect of addition of exercise to therapeutic lifestyle changes diet in enabling women and men with coronary heart disease to reach Adult Treatment Panel III low-density lipoprotein cholesterol goal without lowering high-density lipoprotein cholesterol. Am J Cardiol. 2002;89(10):1201-4.

39. Jenkins DJ, Kendall CW, Faulkner D, et al. A dietary portfolio approach to cholesterol reduction: combined effects of plant sterols, vegetable proteins, and viscous fibers in hypercholesterolemia. Metabolism. 2002;51(12):1596-604.

40. Hjermann I, Velve Byre K, Holme I, et al. Effect of diet and smoking intervention on the incidence of coronary heart disease: report from the Oslo Study Group of a randomised trial in healthy men. Lancet. 1981;2(8259):1303-10.

41. Peacock $P$, et al. The multiple risk factor intervention trial (MRFIT): a national study of primary prevention of coronary heart disease. JAMA. 1976;235(8):825-7.

42. Wanders AJ, Zock PL, Brouwer IA. Trans fat intake and its dietary sources in general populations worldwide: a systematic review. Nutrients. 2017;9(8):840.

43. Egger $M$, Juni $P$, Bartlett $C$, et al. How important are comprehensive literature searches and the assessment of trial quality in systematic reviews? Empir study Health Technol Assess. 2003;7(1):1-76.

44. Schulz KF, Chalmers I, Hayes RJ, et al. Empirical evidence of bias: dimensions of methodological quality associated with estimates of treatment effects in controlled trials. JAMA. 1995;273(5):408-12.

45. Egger M. Systematic reviews in health care: meta-analysis in context. 1995.

46. Schmid CH, Stark PC, Berlin JA, et al. Meta-regression detected associations between heterogeneous treatment effects and study-level, but not patient-level, factors. J Clin Epidemiol. 2004;57(7):683-97.

\section{Publisher's Note}

Springer Nature remains neutral with regard to jurisdictional claims in published maps and institutional affiliations.
Ready to submit your research? Choose BMC and benefit from:

- fast, convenient online submission

- thorough peer review by experienced researchers in your field

- rapid publication on acceptance

- support for research data, including large and complex data types

- gold Open Access which fosters wider collaboration and increased citations

- maximum visibility for your research: over $100 \mathrm{M}$ website views per year

At $\mathrm{BMC}$, research is always in progress.

Learn more biomedcentral.com/submissions 